\title{
Auranofin displays anticancer activity against ovarian cancer cells through FOXO3 activation independent of p53
}

\author{
SEE-HYOUNG PARK ${ }^{1 *}$, JUNG HAN LEE ${ }^{2 *}$, JONATHAN S. BEREK $^{1}$ and MICKEY C.-T. HU ${ }^{1}$ \\ ${ }^{1}$ Division of Gynecologic Oncology, Department of Obstetrics and Gynecology, \\ Stanford University School of Medicine, Stanford, CA 94305, USA; ${ }^{2}$ Department of Obstetrics \\ and Gynecology, Hanyang University School of Medicine, Seoul 133-792, Republic of Korea
}

Received April 20, 2014; Accepted June 11, 2014

DOI: $10.3892 /$ ijo.2014.2579

\begin{abstract}
Auranofin is a gold-containing compound classified by the World Health Organization as a clinically established rheumatoid arthritis therapeutic agent. Through drug screening for novel anticancer therapeutics, we unexpectedly identified auranofin as a potent anticancer agent against a p53-null ovarian carcinoma SKOV3 cell line. However, the molecular mechanism underlying auranofin-mediated anticancer activity in ovarian cancer cells is basically unknown. Here, we show that auranofin inhibits proliferation and survival of SKOV3 cells in a dose- and time-dependent manner. Auranofin treatment activates the pro-apoptotic caspase-3, increases protein levels of apoptosis-inducing proteins Bax and Bim and reduces the expression of the anti-apoptotic mediator Bcl-2 in SKOV 3 cells. Moreover, auranofin downregulates I $\kappa$ B kinase (IKK) $-\beta$ and promotes nuclear localization and the activation of FOXO3 tumor suppressor, leading to cellular apoptosis in SKOV3 cells. In contrast, silencing FOXO3 diminishes the pro-apoptotic signaling of auranofin in SKOV3 cells. These results suggest that auranofin may induce caspase-3-mediated apoptosis in a FOXO3-dependent manner. The observed upregulation of pro-apoptotic genes and apoptosis in cancer cells without p53 in response to auranofin suggests a novel p53-independent mechanism underlying auranofin-induced apoptosis in ovarian cancer cells.
\end{abstract}

\section{Introduction}

Ovarian cancer is the leading cause of gynecologic cancer deaths in the United States (US) (1). While ovarian cancer has

Correspondence to: Dr Mickey C.-T. Hu, Faculty of Division of Gynecologic Oncology, Department of Obstetrics and Gynecology, Stanford University School of Medicine, 300 Pasteur Drive HH333, Stanford, CA 94305, USA

E-mail: mhu1@stanford.edu

"Contributed equally

Key words: auranofin, cancer, FOXO, Forkhead, apoptosis, caspase, Bax, Bim, p53, IкB kinase, tumor suppression a typically good response to first-line combination chemotherapy after initial cytoreductive surgery, the prognosis of patients with advanced malignant ovarian cancer remains poor because of acquired chemotherapy resistance (2). Despite recent advances made in chemotherapies of ovarian cancer, the overall survival of patients has not improved significantly because a considerable number of patients harbor ovarian cancer refractory to these therapies and the majority of the initially responsive tumors become resistant to treatments (3). Thus, the development of novel targeted therapy that retains activity against chemotherapy-resistant ovarian cancer is an unmet and urgent medical need.

Auranofin [2,3,4,6-tetra-o-acetyl-1-thio- $\beta$-D-glucopyranosato-S-(triethyl-phosphine) gold] is a thiol-reactive gold (I)-containing compound (Fig. 1) that reduces the effects of the inflammatory process in the body, and has been utilized to treat rheumatoid arthritis by reducing pain and swelling $(4,5)$. Auranofin can inhibit IgE- and non-IgE-mediated histamine release from human basophils and suppress the de novo synthesis of sulfidopeptide leukotriene C4 (LTC4), which is induced by anti-IgE from basophils and mast cells (6). In addition, auranofin is a potent inhibitor of mitochondrial thioredoxin reductase in vitro and in vivo, since auranofin is able to block its active site (7). In addition, auranofin has been shown to inhibit the activation of the $\mathrm{IKK} / \mathrm{NF}-\kappa \mathrm{B}$ signaling pathway and thereby downregulate the gene expression of pro-inflammatory cytokines such as IL-1 $\beta$ and TNF- $\alpha$ (8-10). Our previous study shows that IKK- $\beta$ activation phosphorylates the serine- 644 residue in the FOXO3 protein and subsequently triggers faster protein degradation of $\mathrm{FOXO} 3$ via the proteasome-mediated ubiquitination (Ub) mechanism, which results in the stimulation of human breast cancer cell proliferation in vitro and the development of breast tumor in vivo $(11,12)$. These findings suggest that IKK- $\beta$ may be a potential target for anticancer therapy through FOXO3 activation. Interestingly, when we screened for small molecules that can promote the activation of FOXO3 in ovarian cancer cells, we identified auranofin as a candidate FOXO3activating small molecule from the US Food and Drug Administration (FDA)-approved compound libraries. Since auranofin is also a candidate inhibitor targeting IKK- $\beta$, it is a promising small molecule candidate for development as anticancer therapeutics. 
FOXO3 is a member of the human Forkhead-box (FOX) gene family that is known to have the distinct Forkhead DNA binding domain (13). As a transcriptional factor, $\mathrm{FOXO} 3$ is known to regulate various cellular processes such as cell cycle $(14,15)$, cellular apoptosis (16-19), DNA damage repair $(20,21)$, stress responses $(15,22,23)$, metabolism (24), aging (25) and tumor suppression in mammalian cells $(12,18,26)$. The results from gene knockout exhibit key functions of FOXO family members in tumor suppression (27) and in preventing the decline of the hematopoietic stem cell pool (28). The FOXO3 protein in cancer cells can be regulated by various protein modification mechanisms such as phosphorylation, acetylation and ubiquitination $(25,29-31)$. It has been shown that several active protein kinases (such as Akt, IKK- $\beta$ and MAPK) display the ability to phosphorylate the specific serine/threonine residues on the $\mathrm{FOXO} 3$ protein and induce the translocation of FOXO3 from the nucleus to the cytoplasm. This nuclear exclusion and translocation of FOXO3 into the cytoplasm inhibits FOXO3-dependent transcription and results in the proteasome-mediated $\mathrm{Ub}$ and protein degradation of $\mathrm{FOXO} 3$ $(11,12,18,25,31)$. This inhibition of function of FOXO3 leads to tumor development and progression, suggesting that FOXO3 is a crucial tumor suppressor. Importantly, several clinical studies on the relationship between the FOXO3 protein nuclear localization or expression level and cancer patient survival rates have revealed that $\mathrm{FOXO} 3$ is a good prognostic biomarker for cancer survival $(12,32-34)$, which suggests that the regulation of FOXO3 activation in cancer cells may be a promising strategy for developing anticancer therapeutic drugs.

Sequential activation of caspases (the cysteinyl aspartatespecific proteases) plays an important role in the execution phase of cellular apoptosis (35). In general, caspases exist as inactive pro-enzymes that undergo proteolytic processing at the conserved aspartic residues to produce two fragments that form a functional dimer as an active protease. It has been shown that cleavage of poly(ADP-ribose) polymerase 1 (PARP1) by caspase-3, a crucial protease in regulating apoptosis, at the pro-apoptotic cleavage site of PARP1 produces the $\mathrm{p} 85-\mathrm{kDa}$ proteolytic fragment, which has been suggested as a biomarker associated with apoptosis $(36,37)$.

In the present study, we used human ovarian carcinoma SKOV3 cells, which are p53-null, as the cell model system to investigate the cytotoxic activity and the anticancer mechanisms of auranofin. Cell-based assays and biochemical analyses were employed to elucidate the molecular mechanism underlying the anticancer activity of auranofin in SKOV3 cells. Based on our findings, we propose that FOXO family members may upregulate the pro-apoptotic genes and downregulate certain cell survival genes that contribute to the cellular apoptosis response to auranofin in a p53-independent manner. The important biological and pathological significance of this new mechanism of auranofin in cancer therapy is discussed below.

\section{Materials and methods}

Chemical reagents and antibodies. Auranofin, dimethylsulfoxide (DMSO), glycerol, glycine, sodium chloride, thiazolyl blue tetrazolium bromide, Trizma base and Tween-20 were purchased from Sigma (St. Louis, MO, USA). Mouse anti-IкB kinase $\beta$ (1:2,000 dilution), mouse anti-IкB $\alpha$ (1:1,000 dilu- tion), rabbit anti-p-IкB $\alpha$ (1:1,000 dilution), mouse anti-PARP1 (1:1,000 dilution) and rabbit anti-FOXO3 (1:1,000 dilution) antibodies were obtained from Santa Cruz Biotechnology (Santa Cruz, CA, USA). Rabbit anti-cleaved caspase-3 (1:1,000 dilution), rabbit anti-Bax (1:1,000 dilution), rabbit anti-Bim (1:1,000 dilution) and rabbit anti-Bcl-2 (1:1,000 dilution) antibodies were purchased from Cell Signaling Technology (Danvers, MA, USA). Mouse anti- $\beta$-actin antibody (1:3,000 dilution) was purchased from Sigma. Goat anti-mouse and goat anti-rabbit horseradish peroxidase-conjugated $\mathrm{IgG}$ were obtained from Jackson ImmunoResearch (West Grove, PA, USA). ECL Western Blotting Detection reagents were obtained from Genedepot (Barker, TX, USA).

Cells, cell culture and siRNA transfection. Human ovarian carcinoma SKOV3 cells (from ATCC) were maintained in DMEM/F12 media supplemented with $10 \%$ fetal bovine serum, $3 \% \mathrm{~L}$-glutamine and $1 \%$ streptomycin/penicillin at $37^{\circ} \mathrm{C}$ in a humidified incubator containing $5 \% \mathrm{CO}_{2}$ in air. FOXO3siRNA and control-siRNA were obtained from Santa Cruz Biotechnology. Cells were transfected with FOXO3-siRNA or control-siRNA by using DharmaFECT 1 transfection reagent (Thermo Scientific, Rockford, IL, USA), according to the manufacturer's instructions and as described previously (19).

MTT cell viability assay. A $200 \mu 1$ aliquot of cells $\left(1 \times 10^{3}\right.$ cells in media) was added to each well of a 96-well plate and incubated for $18 \mathrm{~h}$ at $37^{\circ} \mathrm{C}$ in a humidified incubator containing $5 \% \mathrm{CO}_{2}$ in air. After incubation, each dose $(0,50,100,200$ and $400 \mathrm{nM}$ ) of auranofin was added into the wells for $72 \mathrm{~h}$ for the dose-dependent response assay and $100 \mathrm{nM}$ of auranofin was added into the wells for $0,24,72$ and $120 \mathrm{~h}$ for the timedependent response assay. Control cultures were treated with DMSO. After incubation, a $20 \mu \mathrm{l}$ MTT solution $(5 \mathrm{mg} / \mathrm{ml}$ in phosphate buffer) was added to each well and the incubation continued for $4 \mathrm{~h}$, after which time the solution was carefully removed. The blue crystalline precipitate was dissolved in DMSO $200 \mu$ l. The visible absorbance at $560 \mathrm{~nm}$ of each well was quantified using a microplate reader.

Cell counting assay. SKOV3 cells $\left(1 \times 10^{4}\right)$ were seeded in 6-cm dishes and incubated at $37^{\circ} \mathrm{C}$ in a humidified incubator containing 5\% $\mathrm{CO}_{2}$ in air incubator for $18 \mathrm{~h}$. After incubation, cells were treated with DMSO as control vehicle and the indicated concentration of auranofin $(100 \mathrm{nM})$ for $0,24,72$ and $120 \mathrm{~h}$. Each day, cell numbers were measured by using a hemocytometer.

Colony formation assay. SKOV3 cells $\left(0.5 \times 10^{3}\right)$ were seeded in 6-cm dishes and incubated at $37^{\circ} \mathrm{C}$ in a humidified incubator containing $5 \% \mathrm{CO}_{2}$ in air incubator for $18 \mathrm{~h}$. After incubation, cells were treated with DMSO as control vehicle and the indicated concentration of auranofin $(100 \mathrm{nM})$ for 7 days. The colonies were washed twice with PBS, fixed with $3.7 \%$ paraformaldehyde and stained with $1 \%$ crystal violet solution in distilled water.

Western blot analysis. Western blot analysis was performed as described previously $(11,12,19)$. Briefly, cells were washed with PBS and lysed in lysis buffer (50 mM Tris- $\mathrm{HCl}, 150 \mathrm{mM}$ 


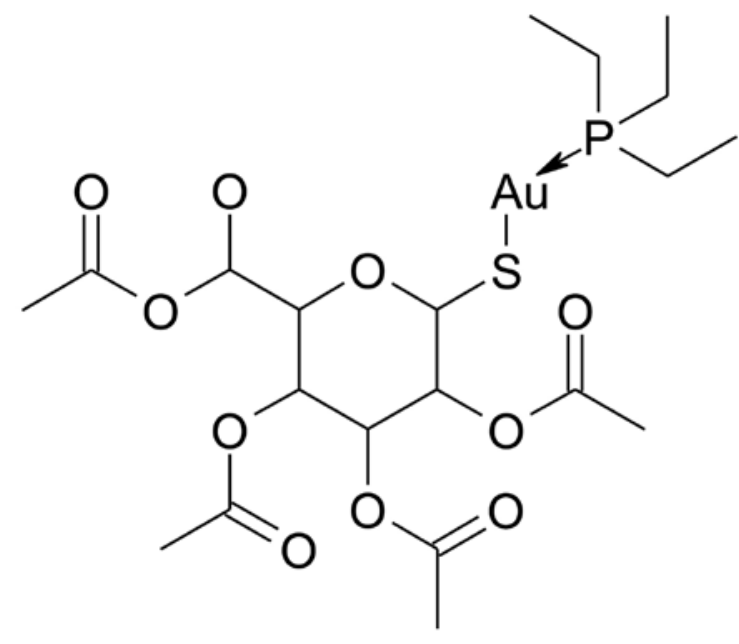

Figure 1. Chemical structure of auranofin.

$\mathrm{NaCl}, 2$ mM EDTA, 1\% Triton X-100, 0.1\% SDS, pH 8.0) with protease and phosphatase inhibitors. Cell lysates were centrifuged $\left(10,000 \mathrm{x} \mathrm{g}, 4^{\circ} \mathrm{C}, 10 \mathrm{~min}\right)$ and the supernatants were separated on 6 or $10 \%$ SDS-PAGE gels and blotted onto nitrocellulose membranes (Bio-Rad Laboratories, Hercules, CA, USA). The membranes were blocked in 3\% non-fat dry milk for $1 \mathrm{~h}$ at room temperature and probed with appropriate antibodies. Membranes were then probed with HRP-tagged anti-mouse or anti-rabbit IgG antibodies diluted 1:5,000$1: 15,000$ in $3 \%$ non-fat dry milk for $1 \mathrm{~h}$ at room temperature. Chemiluminescence was detected using enhanced ECL.

Cytoplasmic and nuclear protein fractionation. Cells from each condition were trypsinized, centrifuged, washed, re-suspended in a cytoplasmic fractional buffer (10 mM HEPES, $\mathrm{pH} 8.0$, $50 \mathrm{mM} \mathrm{NaCl}, 500 \mathrm{mM}$ sucrose, $1 \mathrm{mM}$ EDTA, $0.5 \mathrm{mM}$ spermidine, $0.15 \mathrm{mM}$ spermine, $0.2 \%$ Triton X-100, $1 \mathrm{mM}$ DTT, $2 \mu \mathrm{M}$ PMSF and $0.15 \mathrm{U} / \mathrm{ml}$ aprotinin) and incubated at $4^{\circ} \mathrm{C}$ for $30 \mathrm{~min}$ on a rotator. The cell suspension was centrifuged at $10,000 \mathrm{rpm}$ for $30 \mathrm{~min}$ at $4^{\circ} \mathrm{C}$ and the supernatant was collected for cytoplasmic fraction. The nuclear pellet was washed twice with the washing buffer (10 mM HEPES pH 8.0, $50 \mathrm{mM} \mathrm{NaCl}$, $25 \%$ glycerol, $0.1 \mathrm{mM}$ EDTA, $0.5 \mathrm{mM}$ spermidine and $0.15 \mathrm{mM}$ spermine). The remaining pellet was re-suspended with a nuclear fractional buffer (10 mM HEPES pH 8, $350 \mathrm{mM} \mathrm{NaCl}$, $25 \%$ glycerol, $0.1 \mathrm{mM}$ EDTA, $0.5 \mathrm{mM}$ spermidine and $0.15 \mathrm{mM}$ spermine) and incubated at $4^{\circ} \mathrm{C}$ for $30 \mathrm{~min}$ on a rotator. The nuclear suspension was centrifuged at $13,000 \mathrm{rpm}$ for $30 \mathrm{~min}$ at $4^{\circ} \mathrm{C}$, the supernatant was collected for nuclear fraction. Protein in each fraction was quantified by the Bradford protein determination reagent (Bio-Rad Laboratories), using BSA as a standard.

DNA fragmentation assay. SKOV 3 cells $\left(2 \times 10^{7}\right.$ per sample) were trypsinized, lysed in the lysis buffer $(10 \mathrm{mM}$ Tris- $\mathrm{HCl}$, $10 \mathrm{mM}$ EDTA, 0.1\% Triton-X 100, 0.1\% SDS and $\mathrm{pH} 7.5$ ) and incubated on ice for $30 \mathrm{~min}$. The lysates were digested with RNase I followed by digestion with proteinase $\mathrm{K}$. The DNA was extracted by phenol-chloroform (1:1, v/v), precipitated with 2 volumes of EtOH plus $10 \% \mathrm{NaAc}$ (3 M, pH 5.2) and then dissolved in distilled water. Equal amounts of the extracted DNA ( $2 \mu \mathrm{g} /$ lane) and size markers (1-kb ladder) were subjected to electrophoresis on $2 \%$ agarose gels, which were stained with ethidium bromide and photographed.

Statistical analysis. Results are expressed as arithmetic mean \pm SEM (the standard error of the mean). To compare the statistical meaning between the groups, two-sided unpaired Student's t-test was used. All experiments were repeated three times and the representative data are shown. Statistical analyses were performed using SPSS software (version 19.0, SPSS Inc., Chicago, IL, USA). Mean differences with P-values $<0.05$ were considered statistically significant.

\section{Results}

Auranofin inhibits cell survival or growth of SKOV3 cells. To examine the potential anticancer activity of auranofin against ovarian cancer cells, we treated human ovarian carcinoma SKOV3 cells with auranofin and measured the survival and/ or growth rate of SKOV3 cells using the MTT, cell counting and colony formation assays. We showed that auranofin had an inhibitory effect on SKOV3 cell survival/growth in a dose- and time-dependent manner. After $72 \mathrm{~h}$ incubation, the dose-dependent assay data indicated that the $\mathrm{IC}_{50}$ value of auranofin on SKOV3 was $\sim 150 \mathrm{nM}$ (Fig. 2A), which is thought to be relatively low. The time-dependent assay results also demonstrated the anti-survival/ proliferation activity of auranofin (Fig. 2B), which was confirmed by cell counting assay using the same treatment condition of auranofin against SKOV3 cells (Fig. 3). After $120 \mathrm{~h}$ incubation, the cell number in SKOV3 cells treated with auranofin $(100 \mathrm{nM})$ was significantly lower ( 13 times) than that of the control (DMSO) treatment. Furthermore, the clonogenic assay results showed that auranofin treatment significantly suppressed the colony-forming ability of SKOV3 cells (Fig. 4). Taken together, these results support that auranofin displays a potent inhibitory effect on cell survival/proliferation of ovarian carcinoma SKOV3 cells.

Auranofin induces cellular apoptosis in SKOV3 cells. To examine the effect of auranofin on apoptosis in SKOV3 cells, we performed western blot analyses and DNA fragmentation assays. We found that the auranofin treatment (100 $\mathrm{nM}$ for $48 \mathrm{~h}$ ) increased the cleavage of PARP1 and caspase-3. Auranofin also upregulated the expression of Bax and Bcl-2 interacting mediator of cell death (Bim) in SKOV3 cells as compared with the DMSO control treatment, whereas the auranofin treatment decreased the Bcl-2 expression level under the same condition (Fig. 5A). These results suggest that auranofin may exhibit its apoptotic effect through the caspase-3-mediated mechanism in SKOV3 cells, the upregulation of the mitochondrial proapoptotic Bax and Bim proteins and the downregulation of the anti-apoptotic $\mathrm{Bcl} 2$ protein expression. Also, when compared with the DMSO control, treatment of SKOV3 cells with auranofin $(100 \mathrm{nM})$ for $48 \mathrm{~h}$ resulted in an increase in the amount of DNA fragmentation, a typical marker of apoptosis caused by the cleaved (active) caspase-3 (Fig. 5B). Collectively, our results show that auranofin treatment can induce cellular apoptosis in SKOV3 cells.

Auranofin downregulates the expression of IKK- $\beta$ and induces the nuclear translocation of FOXO3 protein in SKOV3 cells. 


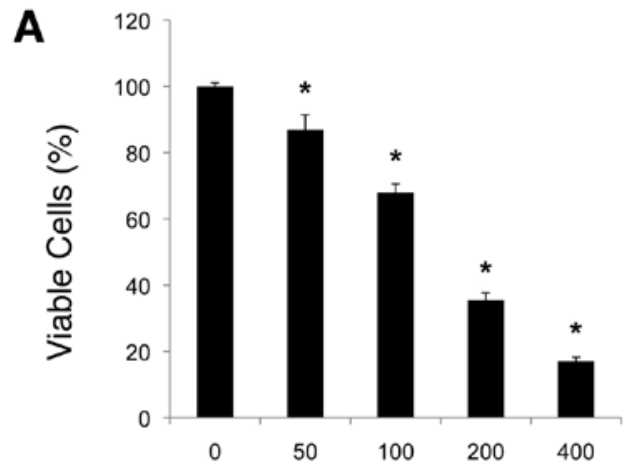

Dose of auranofin $(\mathrm{nM})$

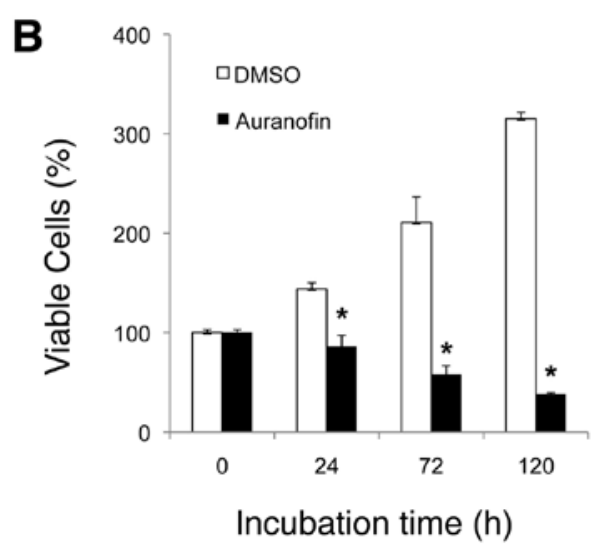

Figure 2. The cytotoxic effect of auranofin on SKOV3 cells. (A) The dosedependent effect of auranofin $(0,50,100,200$ and $400 \mathrm{nM})$ on SKOV3 cells after 72-h incubation. (B) The time-dependent effect of auranofin (100 nM) on SKOV3 cells after 0, 24, 72 and $120 \mathrm{~h}$. The cell viability was determined by the MTT assay and the relative cell survival rate percentage was calculated by dividing the optical density of each auranofin treatment by the optical density of the control (DMSO) treatment. The significant P-values between the auranofin group versus the control group are indicated $\left({ }^{*} \mathrm{P}<0.001\right)$. The results are based on three replicates. The error bars represent standard deviation by paired t-test.

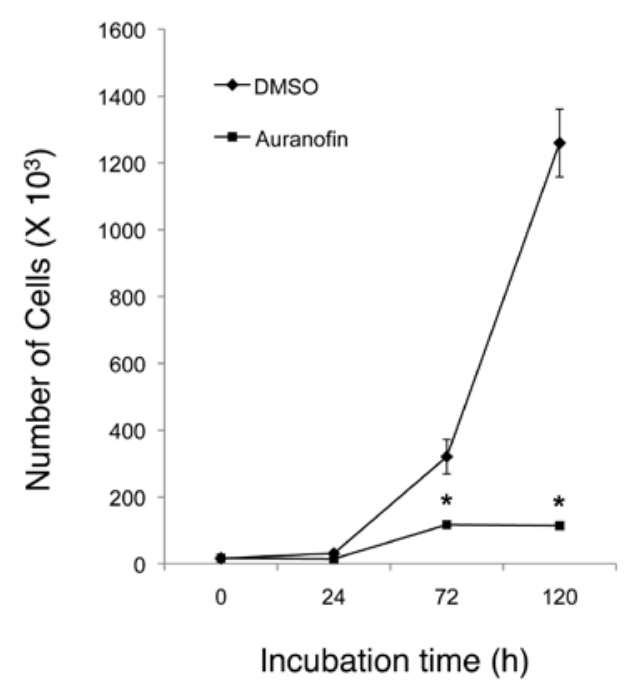

Figure 3. Auranofin inhibits cell survival or growth of SKOV3 cells. The cell numbers were determined by the cell counting assay after SKOV3 cells $\left(1 \times 10^{4}\right.$ cells/plate) were treated with auranofin $(100 \mathrm{nM})$ or the control (DMSO) for 0, 24, 72 and $120 \mathrm{~h}$. The significant P-values between the auranofin group versus the control group are indicated $\left({ }^{*} \mathrm{P}<0.001\right)$. The results are based on three replicates. The error bars represent standard deviation by paired t-test.
A
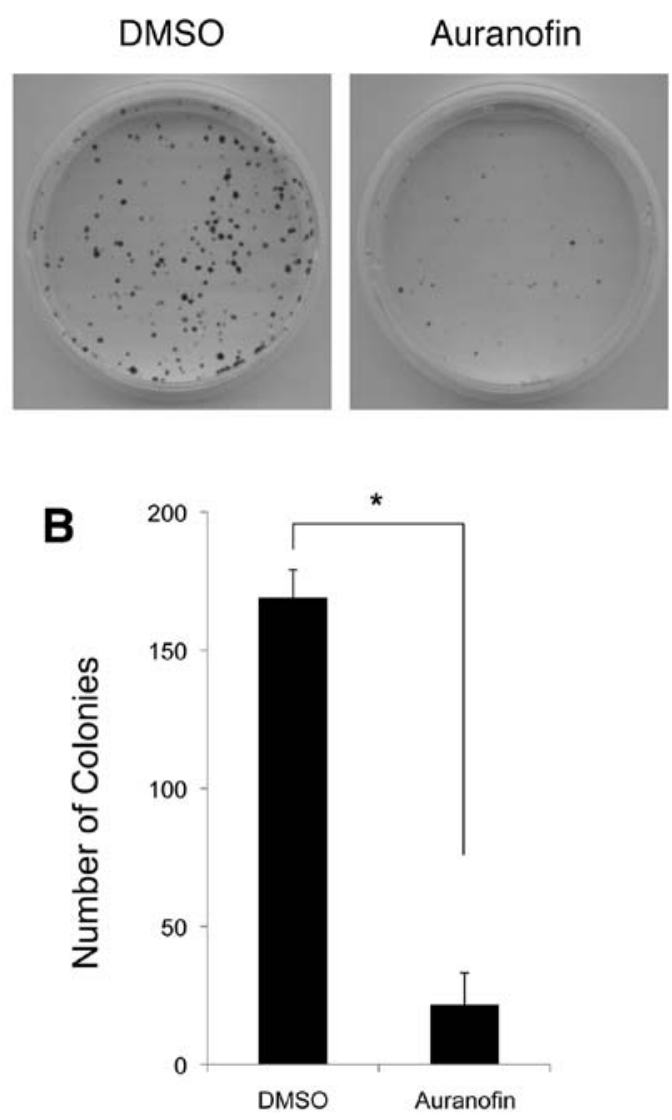

Figure 4. Auranofin suppresses the colony-forming ability of SKOV3 cells. The colony numbers were determined by the colony formation assay. (A) SKOV3 cells (500 cells/plate) were treated with auranofin $(100 \mathrm{nM})$ or the control (DMSO) for 7 days and stained with crystal violet solution. The representative images of the assays are shown. (B) The numbers of colonies in the auranofin-treated plates were compared with those of the controltreated plates. The results are the mean \pm SEM numbers of cell colonies of three replicates. ${ }^{*} \mathrm{P}<0.001$.

To elucidate the anticancer mechanism of auranofin treatment against SKOV3 cells, we carried out western blot analyses with cytoplasmic and nuclear extracts that had been fractionated from SKOV3 cells previously treated with auranofin. We showed that auranofin treatment $(0,25,50$ and $100 \mathrm{nM}$ for $48 \mathrm{~h}$ ) decreased the expression level of IKK- $\beta$ protein in the cytoplasm in a dose-dependent manner. These data were confirmed by a parallel decrease of the phosphorylation level of IкB $\alpha$, which is a well-known substrate of IKK- $\beta$, while the total amount of IкB $\alpha$ protein was not affected by auranofin treatment (Fig. 6). At the same time, the level of the cytoplasmic $\mathrm{FOXO} 3$ protein was decreased by auranofin treatment, while the level of the nuclear FOXO3 protein was significantly increased in a dose-dependent manner (Fig. 6). These results suggest that auranofin may display its anticancer effect through downregulation of IKK- $\beta$, which then triggers the translocation of the FOXO3 protein from the cytoplasm into the nucleus of ovarian cancer cells.

Auranofin promotes apoptosis in SKOV3 cells in a FOXO3dependent manner. To examine the role of $\mathrm{FOXO} 3$ in auranofin-induced apoptosis in SKOV3 cells, we silenced FOXO3 expression in SKOV3 cells and analyzed the protein 
A

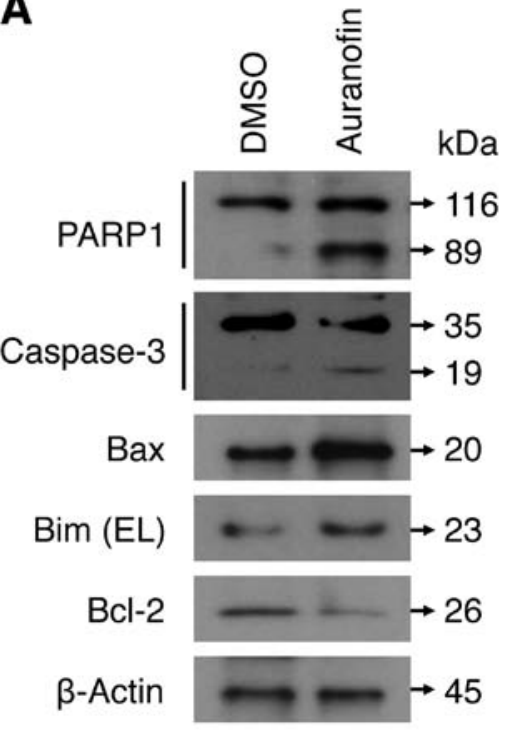

B

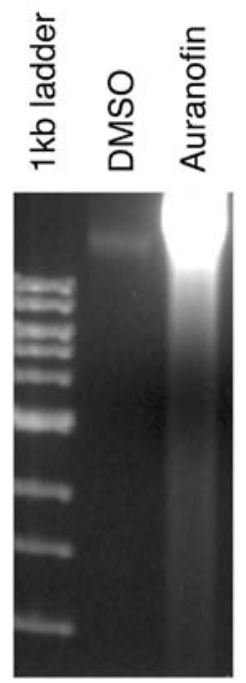

Figure 5. Auranofin induces cellular apoptosis in SKOV3 cells. (A) SKOV3 cells were treated with auranofin $(100 \mathrm{nM})$ or control (DMSO) for $48 \mathrm{~h}$. Total lysates of cells were analyzed by western blot analysis with specific antibodies against apoptosis-related proteins as indicated. $\beta$-actin represents the loading controls. (B) DNA samples extracted from SKOV3 cells, which were treated with auranofin or control as described above, and subjected to DNA fragmentation assay. Equal amounts of the extracted DNA ( $2 \mu \mathrm{g} / \mathrm{lane})$ and size markers (1-kb ladder) were subjected to electrophoresis on $2 \%$ agarose gels, which were stained with ethidium bromide and photographed.

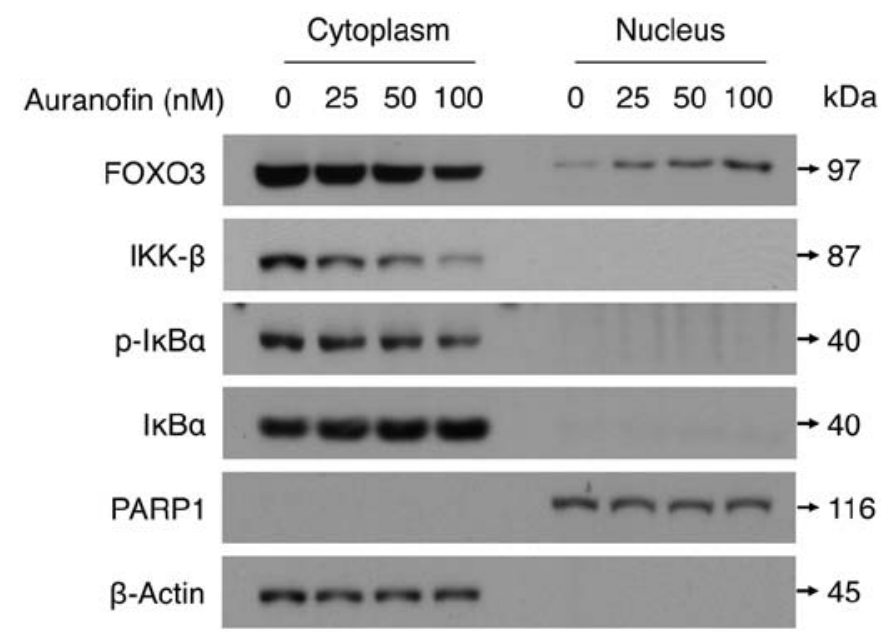

Figure 6. Auranofin downregulates IKK- $\beta$ expression and promotes the nuclear translocation of FOXO3 protein in SKOV3 cells. SKOV3 cells were treated with auranofin $(25,50$ and $100 \mathrm{nM})$ or control $(0 \mathrm{nM})$ for $48 \mathrm{~h}$ and cytoplasmic and nuclear extracts that had been fractionated from cells were analyzed by western blot analysis with specific antibodies as indicated. $\beta$-actin and PARP1 represent the loading controls of cytoplasmic and nuclear extracts, respectively.

status of PARP1, caspase-3, Bax, Bim, Bcl-2 and FOXO3 using western blot assays. Interestingly, knockdown of FOXO3 expression in SKOV3 cells significantly attenuated the caspase3 -mediated cleavage of PARP1 and caspase-3 proteins and reduced the expression levels of Bax and Bim, extra large (EL) isoform, when these cells were treated with auranofin (Fig. 7). In contrast, silencing FOXO3 decreases the repressive effect

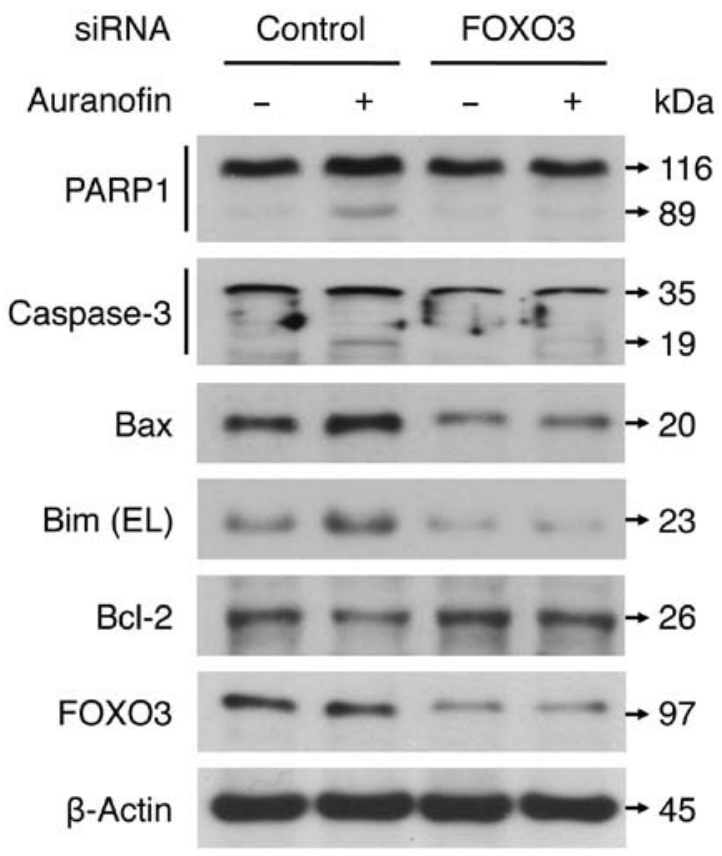

Figure 7. FOXO3 is essential for auranofin-mediated apoptosis in SKOV3 cells. SKOV3 cells were transfected with control-siRNA or FOXO3-siRNA for $24 \mathrm{~h}$ as described in Materials and methods. Subsequently, the transfected cells were treated with auranofin $(100 \mathrm{nM})$ or control (DMSO) for $48 \mathrm{~h}$ and total lysates of cells were analyzed by western blot analysis with specific antibodies against apoptosis-related proteins as indicated. $\beta$-actin represents the loading controls.

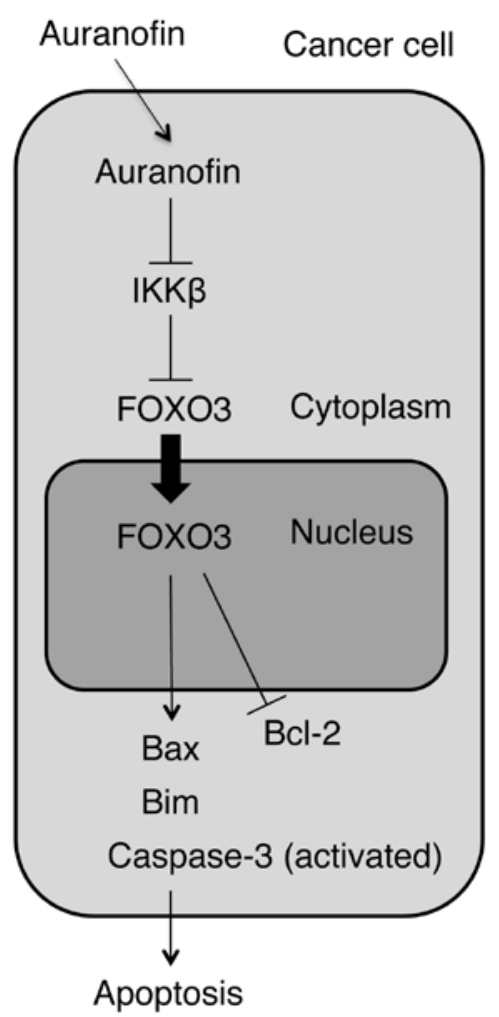

Figure 8. A diagram represents the model for the FOXO3-dependent anticancer function of auranofin. A schematic shows that auranofin inhibits IKK- $\beta$ and leads to FOXO3 translocation from the cytoplasm into the nucleus to upregulate the expression of Bax and Bim pro-apoptotic proteins, as well as to downregulate of the expression of Bcl-2 anti-apoptotic protein. In addition, auranofin induces the activation of caspase- 3 protein in a FOXO3dependent manner. As a result of this FOXO3-mediated apoptotic pathway, auranofin promotes cancer cell apoptosis. 
of auranofin on Bcl-2 expression. Collectively, these results suggest that FOXO3 may play an essential role in promoting the caspase-3-mediated apoptosis after auranofin treatment in SKOV 3 cells.

\section{Discussion}

FOXO3 has received great attention as a potential prognostic biomarker for overall survival in patients with cancer because several clinical studies with primary tumor specimens have indicated that FOXO3's nuclear exclusion or downregulation correlates significantly with poor prognosis and survival in breast and ovarian carcinomas $(12,32-34)$. These findings also suggest that small molecules that can induce nuclear localization (activation) of FOXO3 in cancer cells may become promising antitumor chemotherapeutic drugs. The promotion of nuclear localization of the FOXO transcription factors by gold-containing compounds such as auranofin has not been reported and the roles of FOXO transcription factors in auranofin-mediated cellular apoptosis have not been determined. In this study, our results provide the first evidence that auranofin promotes the $\mathrm{FOXO} 3$ protein to translocate from the cytoplasm into the nucleus, where it upregulates the expression of the target genes Bax and Bim and downregulates the expression of Bcl-2 (an important gene regulating cell survival) in ovarian cancer cells. Because this phenomenon is discovered in a p53-null cell line SKOV3, it suggests that activation of FOXO3, Bax and Bim by auranofin may be through a mechanism independent of p53. It is known that the tumor suppressor p53 plays a key role in genotoxic stress responses including repair of DNA damage, cell cycle arrest and apoptosis, which are complicated and mostly through a p53-dependent pathway (38-40). Therefore, we propose a new mechanism by which FOXO3 induces apoptosis in ovarian cancer cells in response to auranofin treatment through upregulation of Bax and Bim and downregulation of Bcl-2 in a p53-independent manner (Fig. 8).

We found that auranofin treatment increased the cleavage of PARP1 and caspase-3 in SKOV3 cells, while the level of parental caspase-3 protein appear to be not significantly affected by auranofin treatment (Figs. 5A and 7). These results suggest that auranofin may exhibit caspase-3-mediated apoptotic effect through the activation of caspase- 3 protein instead of through the upregulation of caspase-3 expression in SKOV3 cells. Interestingly, silencing the expression of FOXO3 in SKOV3 cells significantly reduced the caspase-3-mediated cleavage of PARP1 and caspase-3 proteins (Fig. 7). Currently, there is no literature to our knowledge that demonstrates FOXO3 is required for the caspase-3-mediated cleavage of PARP1 and caspase- 3 proteins and for auranofin-induced apoptotic signaling in cancer cells. However, it remains largely unknown how $\mathrm{FOXO} 3$ regulates the activation of caspase- 3 protein in cancer cells in response to auranofin treatment. It is of interest to further elucidate the molecular mechanisms governing the control of the FOXO3-mediated activation of caspase-3 protein in promoting the apoptotic signaling pathways in cancer cells.

As an anti-rheumatoid arthritis agent, auranofin has been shown to inhibit the activation of NF- $\kappa B$ by blocking IKK activity in the LPS-stimulated RAW 264.7 mouse macrophages (8). In this study, our results provide initial evidence of the anticancer effect of auranofin on human ovarian cancer cells, in which auranofin treatment downregulates the expression of IKK- $\beta$ and reduces the level of phospho-

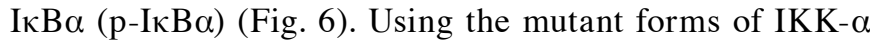
and IKK- $\beta$ subunits, Jeon et al suggest a possible inhibitory mechanism to explain how auranofin inhibited IKK activity in vitro (8). According to their report, a substitution of cystine-179 of IKK- $\beta$ with alanine (mutant IKK- $\beta$-179A) made IKK- $\beta$ resistant to inhibition by auranofin. However, a similar protective effect was not observed with IKK- $\alpha$ mutant. This result indicates that auranofin inhibited the two subunits of IKK in a different mode and that the inhibition of IKK activation induced by inflammatory signals in the auranofin-treated cells may be via its interaction with cystine-179 of IKK- $\beta$. It will be interesting to examine whether or not auranofin treatment exhibits an inhibitory effect on mutant IKK- $\beta-179 A$ activity in human cancer cells. Previously, our laboratory identified a novel mechanism by which cancer cells can impair the tumor suppressive function of $\mathrm{FOXO} 3$ protein by the oncogenic IKK- $\beta$-mediated phosphorylation of the serine-644 residue in FOXO3 (FOXO3-pS644) protein that leads to the translocation of $\mathrm{FOXO} 3$ from the nucleus into the cytoplasm in cancer cells $(11,12)$. Subsequently, $\beta \operatorname{TrCP} 1$, an E3 Ub-ligase, interacts with the FOXO3-pS644 protein and induces the Ub-mediated degradation of $\mathrm{FOXO} 3$, resulting in the promotion of tumorigenesis and tumor growth in vivo (11). This IKK- $\beta$-mediated tumorigenic mechanism is consistent with and supports our current finding that auranofin treatment can downregulate the expression of IKK- $\beta$ and promote FOXO3 nuclear localization to regulate the expression of its downstream target genes, resulting in the suppression of cell survival/growth and the promotion of cellular apoptosis in ovarian cancer cells.

From the standpoint of cancer therapy, the initial standard surgical management certainly plays an important and essential role in ovarian cancer treatment. Most patients will have appropriate surgical staging followed by optimal surgical cytoreduction, with the goal being to remove all gross disease before starting chemotherapy (2). There are a number of important issues to be resolved in the management of ovarian cancer that relates to surgery, including the role of surgical interval cytoreduction, as well as the role of second-look laparotomy (3). There are basically three initial chemotherapy options considered the standard of care at the present time for the treatment of ovarian cancer. The first is the use of carboplatin and paclitaxel. The second is a cisplatin and paclitaxel regimen. The third is the use of a carboplatin and docetaxel regimen. Unfortunately, in the second-line setting for the treatment of ovarian cancer, we have far fewer encouraging data based upon randomized controlled trials that give us definitive answers as to optimal management in the malignancy. A considerable number of patients harbor ovarian tumor refractory to these therapies and the majority of the initially responsive tumors become resistant to treatments (41). Thus, the development of novel targeted therapy that retains activity against chemotherapy-resistant ovarian cancer is an unmet medical need. Since auranofin is an FDA-approved small-molecule drug, it can be expedited for future clinical trials as a promising anticancer therapeutics and save time and money for the required pre-clinical investigation and toxicity testing for new compounds (42). 
Finally, further investigation of the signaling mechanisms by which auranofin downregulates the expression of antiapoptotic proteins IKK- $\beta$ and Bcl- 2 that in turn contributes to tumor cell survival/growth may provide new cellular targets that can be exploited therapeutically. On the other hand, further elucidation of the molecular mechanisms underlying the FOXO3-mdiated pro-apoptotic signaling pathways induced by auranofin is necessary for understanding the molecular basis of auranofin anticancer activity and its application as a new anticancer therapy.

\section{Acknowledgements}

We thank the Freidenrich Center for Translational Research for generously providing support. This study was supported in part by R01 grant CA113859 (to M.C.T.H.) from the National Cancer Institute, National Institutes of Health, the 2012 Developmental Cancer Research Award from Stanford Cancer Institute (to M.C.T.H.), a grant 02-2013-051 from the Avon Foundation for Women (to M.C.T.H.), and the 2012 Ann Schreiber Research Award from the Ovarian Cancer Research Fund (to S.H.P.).

\section{References}

1. Siegel R, Naishadham D and Jemal A: Cancer statistics, 2012. CA Cancer J Clin 62: 10-29, 2012.

2. Banerjee $S$ and Kaye SB: New strategies in the treatment of ovarian cancer: current clinical perspectives and future potential. Clin Cancer Res 19: 961-968, 2013.

3. Shigetomi H, Higashiura Y, Kajihara $\mathrm{H}$ and Kobayashi $\mathrm{H}$ : Targeted molecular therapies for ovarian cancer: an update and future perspectives. Oncol Rep 28: 395-408, 2012.

4. Snyder RM, Mirabelli CK and Crooke SJ: The cellular pharmacology of auranofin. Semin Arthritis Rheum 17: 71-80, 1987.

5. Madeira JM, Gibson DL, Kean WF and Klegeris A: The biological activity of auranofin: implications for novel treatment of diseases. Inflammopharmacology 20: 297-306, 2012.

6. Columbo M, Galeone D, Guidi G, Kagey-Sobotka A, Lichtenstein LM, Pettit GR and Marone G: Modulation of mediator release from human basophils and pulmonary mast cells and macrophages by auranofin. Biochem Pharmacol 39: 285-2891, 1990.

7. Rigobello MP, Scutari G, Boscolo R and Bindoli A: Induction of mitochondrial permeability transition by auranofin, a gold(I)phosphine derivative. Br J Pharmacol 136: 1162-1168, 2002.

8. Jeon KI, Jeong JY and Jue DM: Thiol-reactive metal compounds inhibit NF- $\kappa \mathrm{B}$ activation by blocking I $\kappa \mathrm{B}$ kinase. J Immunol 164: 5981-5989, 2000

9. Kim IS, Jin JY, Lee IH and Park SJ: Auranofin induces apoptosis and when combined with retinoid acid enhances differentiation of acute promyelocytic leukaemia cells in vitro. Br J Pharmacol 142: 749-755, 2004

10. Park SJ and Kim IS: The role of p38 MAPK activation for auranofin-induced apoptosis of human promyelocytic leukaemia HL-60 cells. Br J Pharmacol 146: 506-513, 2005.

11. Tsai WB, Chung YM, Zou Y, Park SH, Xu Z, Nakayama K, Lin $\mathrm{SH}$ and $\mathrm{Hu} \mathrm{MC}$ : Inhibition of $\mathrm{FOXO} 3$ tumor suppressor function by $\beta \operatorname{TrCP} 1$ through ubiquitin-mediated degradation in a tumor mouse model. PLoS One 5: e11171, 2010.

12. Hu MC, Lee DF, Xia W, Golfman LS, Ou-Yang F, Yang JY, Zou Y, Bao S, Hanada N, Saso H, Kobayashi R and Hung MC: IkappaB kinase promotes tumorigenesis through inhibition of forkhead FOXO3a. Cell 117: 225-237, 2004.

13. Katoh M and Katoh M: Human FOX gene family. Int J Oncol 25: 1495-1500 2004.

14. Alvarez B, Martinez AC, Burgering BM and Carrera AC: Forkhead transcription factors contribute to execution of the mitotic programme in mammals. Nature 413: 744-747, 2001.

15. Furukawa-Hibi Y, Kobayashi Y, Chen C and Motoyama N: FOXO transcription factors in cell-cycle regulation and the response to oxidative stress. Antioxid Redox Signal 7: 752-760, 2005.
16. Brunet A, Bonni A, Zigmond MJ, Lin MZ, Juo P, Hu LS, Anderson MJ, Arden KC, Blenis J and Greenberg ME: Akt promotes cell survival by phosphorylating and inhibiting a Forkhead transcription factor. Cell 96: 857-868, 1999.

17. Sunters A, Fernández de Mattos S, Stahl M, Brosens JJ, Zoumpoulidou G, Saunders CA, Coffer PJ, Medema RH, Coombes RC and Lam EW: FOXO3 transcriptional regulation of Bim controls apoptosis in paclitaxel-treated breast cancer cell lines. J Biol Chem 278: 49795-49805, 2003.

18. Fu Z and Tindall DJ: FOXOs, cancer and regulation of apoptosis. Oncogene 27: 2312-2319, 2008.

19. Chung YM, Park SH, Tsai WB, Wang SY, Ikeda MA, Berek JS, Chen DJ and Hu MC: FOXO3 signalling links ATM to the p53 apoptotic pathway following DNA damage. Nat Commun 3: $1000,2012$.

20. Tran H, Brunet A, Grenier JM, Datta SR, Fornace AJ Jr, DiStefano PS, Chiang LW and Greenberg ME: DNA repair pathway stimulated by the forkhead transcription factor FOXO3a through the Gadd45 protein. Science 296: 530-534, 2002.

21. Tsai WB, Chung YM, Takahashi Y, Xu Z and Hu MC: Functional interaction between FOXO3 and ATM regulates DNA damage response. Nat Cell Biol 10: 460-467, 2008.

22. Yang J-Y, Xia W and Hu MC: Induction of FOXO3a and Bim expression in response to ionizing radiation. Int $\mathbf{J}$ Oncol 29: 643-648, 2006

23. Sunters A, Madureira PA, Pomeranz KM, Aubert M, Brosens JJ, Cook SJ, Burgering BM, Coombes RC and Lam EW: Paclitaxelinduced nuclear translocation of FOXO3 in breast cancer cells is mediated by c-Jun NH2-terminal kinase and Akt. Cancer Res 66: 212-220, 2006

24. Nemoto S, Fergusson MM and Finkel T: Nutrient availability regulates SIRT1 through a forkhead-dependent pathway. Science 306: 2105-2108, 2004.

25. Greer EL and Brunet A: FOXO transcription factors at the interface between longevity and tumor suppression. Oncogene 24: 7410-7425, 2005

26. Seoane J, Le HV, Shen L, Anderson SA and Massagué J: Integration of Smad and forkhead pathways in the control of neuroepithelial and glioblastoma cell proliferation. Cell 117: 211-223, 2004.

27. Paik JH, Kollipara R, Chu G, Ji H, Xiao Y, Ding Z, Miao L, Tothova Z, Horner JW, Carrasco DR, Jiang S, Gilliland DG, Chin L, Wong WH, Castrillon DH and DePinho RA: FoxOs are lineage-restricted redundant tumor suppressors and regulate endothelial cell homeostasis. Cell 128: 309-323, 2007.

28. Miyamoto K, Araki KY, Naka K, Arai F, Takubo K, Yamazaki S, Matsuoka S, Miyamoto T, Ito K, Ohmura M, Chen C, Hosokawa K, Nakauchi H, Nakayama K, Nakayama KI, Harada M, Motoyama N, Suda T and Hirao A: FOXO3 is essential for maintenance of the hematopoietic stem cell pool. Cell Stem Cell 1: 101-112, 2007.

29. Huang $\mathrm{H}$ and Tindall DJ: FOXO factors: a matter of life and death. Future Oncol 2: 83-89, 2006.

30. Hu MC and Hung MC: Role of IkappaB kinase in tumorigenesis. Future Oncol 1: 67-78, 2005.

31. Eijkelenboom A and Burgering BM: FOXOs: signalling integrators for homeostasis maintenance. Nat Rev Mol Cell Biol 14: 83-97, 2013.

32. Lu M, Zhao Y, Xu F, Wang Y, Xiang J and Chen D: The expression and prognosis of FOXO3a and Skp2 in human ovarian cancer. Med Oncol 29: 3409-3915, 2012.

33. Fei M, Zhao Y, Wang Y, Lu M, Cheng C, Huang X, Zhang D, $\mathrm{Lu} \mathrm{J}, \mathrm{He} \mathrm{S}$ and Shen A: Low expression of Foxo3a is associated with poor prognostic in ovarian cancer patients. Cancer Invest 27: 52-59, 2009.

34. Habashy HO, Rakha EA, Aleskandarany M, Ahmed MA, Green AR, Ellis IO and Powe DG: FOXO3a nuclear localization is associated with good prognosis in luminal-like breast cancer. Breast Cancer Res Treat 129: 11-21, 2011

35. Nicholson DW: Caspase structure, proteolytic substrates, and function during apoptotic cell death. Cell Death Differ 6: 1028-1042, 1999.

36. Lazebnik YA, Kaufmann SH, Desnoyers S, Poirier GG and Earnshaw WC: Cleavage of poly(ADP-ribose) polymerase by a proteinase with properties like ICE. Nature 371: 346-347, 1994.

37. Kumari SR, Mendoza-Alvarez H and Alvarez-Gonzalez R: Functional interactions of p53 with poly(ADP-ribose) polymerase (PARP) during apoptosis following DNA damage: covalent poly(ADP-ribosyl)ation of $\mathrm{p} 53$ by exogenous PARP and noncovalent binding of $\mathrm{p} 53$ to the $\mathrm{M}(\mathrm{r}) 85,000$ proteolytic fragment. Cancer Res 58: 5075-5078, 1998. 
38. Carvajal LA and Manfredi JJ: Another fork in the road - life or death decisions by the tumour suppressor p53. EMBO Rep 14: 414-421, 2013.

39. Yoshida K and Miki Y: The cell death machinery governed by the p53 tumor suppressor in response to DNA damage. Cancer Sci 101: 831-835, 2010.

40. Das S, Boswell SA, Aaronson SA and Lee SW: P53 promoter selection: choosing between life and death. Cell Cycle 7: 154-157, 2008.
41. Fung-Kee-Fung M, Oliver T, Elit L, Oza A, Hirte HW and Bryson P: Optimal chemotherapy treatment for women with recurrent ovarian cancer. Curr Oncol 14: 195-208, 2007.

42. Chong CR and Sullivan DJ Jr: New uses for old drugs. Nature 448: 645-646, 2007. 